OPEN ACCESS

Edited by:

Wan-Jie Gu,

Nanjing Drum Tower Hospital, China

Reviewed by:

Hassan Soleimanpour, Tabriz University of Medical

Sciences, Iran

Shervin Farahmand, Tehran University of Medical Sciences, Iran

*Correspondence: Shuangyan $\mathrm{Hu}$ sxhsy2021@163.com

Specialty section: This article was submitted to Intensive Care Medicine and

Anesthesiology,

a section of the journal

Frontiers in Medicine

Received: 08 May 2021 Accepted: 22 December 2021

Published: 17 January 2022

Citation:

Zhong J, Hu J, Mao L, Ye G, Qiu K,

Zhao $Y$ and Hu S (2022) Efficacy of Intravenous Lidocaine for Pain Relief in

the Emergency Department: A Systematic Review and Meta-Analysis. Front. Med. 8:706844.

doi: 10.3389/fmed.2021.706844

\section{Efficacy of Intravenous Lidocaine for Pain Relief in the Emergency Department: A Systematic Review and Meta-Analysis}

\author{
Junfeng Zhong ${ }^{1}$, Junfeng $\mathrm{Hu}^{1}{ }^{\text {, Linling Mao }}{ }^{1}$, Gang $\mathrm{Ye}^{1}{ }^{1}, \mathrm{Kai}_{\mathrm{Q}} \mathrm{Qi}^{1}{ }^{1}$, Yuhong Zhao ${ }^{1}$ and \\ Shuangyan $\mathrm{Hu}^{2 *}$ \\ ${ }^{1}$ Department of Pain Medicine, Shaoxing People's Hospital, Shaoxing, China, ${ }^{2}$ Department of Anesthesiology, Shaoxing \\ Peoples's Hospital, Shaoxing, China
}

Objective: To compare the efficacy of intravenous (IV) lidocaine with standard analgesics (NSAIDS, opioids) for pain control due to any cause in the emergency department.

Methods: The electronic databases of PubMed, Embase, ScienceDirect, CENTRAL, and Google Scholar were explored from 1st January 2000 to 30th March 2021 and randomized controlled trials (RCTs) comparing IV lidocaine with a control group of standard analgesics were included.

Results: Twelve RCTs including 1,351 patients were included. The cause of pain included abdominal pain, renal or biliary colic, traumatic pain, radicular low back pain, critical limb ischemia, migraine, tension-type headache, and pain of unknown origin. On pooled analysis, we found no statistically significant difference in pain scores between IV lidocaine and control group at $15 \mathrm{~min}$ (MD: $-0.2495 \% \mathrm{Cl}:-1.08,0.61 \mathrm{l}^{2}=81 \%$ $p=0.59), 30 \min \left(\mathrm{MD}:-0.2495 \% \mathrm{Cl}:-1.03,0.55 l^{2}=86 \% p=0.55\right), 45 \mathrm{~min}(\mathrm{MD}:$ $0.3195 \% \mathrm{Cl}:-0.66,1.29 \mathrm{l}^{2}=66 \% p=0.53$ ), and $60 \mathrm{~min}(\mathrm{MD}: 0.5995 \% \mathrm{Cl}:-0.26$, $\left.1.44 R^{2}=75 \% p=0.18\right)$. There was no statistically significant difference in the need for rescue analgesics between the two groups (OR: 1.45 95\% Cl: $0.82,2.56 R^{2}=41 \%$ $p=0.20$ ), but on subgroup analysis, the need for rescue analgesics was significantly higher with IV lidocaine in studies on abdominal pain but not for musculoskeletal pain. On meta-analysis, there was no statistically significant difference in the incidence of side-effects between the two study groups (OR: 1.09 95\% Cl: $0.59,2.02 R^{2}=48 \%$ $p=0.78)$.

Conclusion: IV lidocaine can be considered as an alternative analgesic for pain control in the ED. However, its efficacy may not be higher than standard analgesics. Further RCTs with a large sample size are needed to corroborate the current conclusions.

Keywords: lidocaine, pain, emergency, analgesic, intravenous 


\section{INTRODUCTION}

One of the most frequently encountered complaints in the emergency department (ED) is pain (1). Indeed, early and comprehensive treatment of pain in such a setting is integral to obtaining a high level of patient satisfaction and care. Opioids have been the most frequently prescribed drugs in the ED for pain management (2). Notwithstanding, with the rising incidence of opioid abuse, clinicians are now judicious in the prescription of these drugs in the ED and there is an urgent need for an equally efficacious substitute to manage pain in an urgent setting (3). While the short-term prescription of opioids is not expected to cause drug dependence in itself, there have been apprehensions that the use of opioids in the ED would lead to repeated opioid use in the future, thereby acting as a possible trigger for drug abuse $(4,5)$. Furthermore, the availability of an alternative drug to opioids with proven efficacy and safety profile would be beneficial in a special group of individuals like older adults, drug addicts, patients with prior history of drug abuse or mental health issues, and long-term opioid users $(6,7)$.

Lidocaine is a widely used amide local anesthetic that acts by blocking $\mathrm{Na}$ channels in the central and peripheral neurons of the nociceptive pathway (8). While lidocaine is commonly used for nerve blocks and infiltration anesthesia, the drug also acts an analgesic when administered intravenously (IV) (9). Several RCTs have shown that the use of IV lidocaine significantly reduces postoperative opioid consumption, decreases pain intensity, and shortens hospital stay in surgical patients (10, 11). A meta-analysis of 26 studies by Zhu et al. (12) have demonstrated that IV lidocaine is effective for the management of patients with neuropathic pain. Another review by Lee et al. (13) has shown that IV lidocaine can be used for refractory cancer pain wherein standard analgesic agents are ineffective. While there have been several trials assessing the efficacy of lidocaine for pain relief, its use in an emergency setting is sparsely reported. In a review article published in 2014, Golzari et al. (14) have summarized evidence on the use of lidocaine in an ED setting. The authors noted that lidocaine has been used via several routes including IV, topical, subcutaneous and intra-articular, and for a variety of different indications in the ED but with variable efficacy. Furthermore, there is no clarity on how each route of administration of lidocaine differs from the other.

To the best of our knowledge, to date, only a few systematic reviews have assessed the efficacy of IV lidocaine in the ED. Two studies by Silva et al. (15) and Masic et al. (16) have analyzed the efficacy of IV lidocaine for all pain indications in the ED while another review by Miller et al. (17) assessed the analgesic effect of IV lidocaine for renal colics. However, a major limitation of these reviews is that they could include only a limited number of randomized controlled trials (RCTs) and some even combined evidence with case reports and case series. Furthermore, no metaanalysis could be carried out in any of these reviews. Thus, no level-1 high-quality evidence on the efficacy of lidocaine as an alternative non-opioid drug is available for clinicians managing patients in an emergency setting. In view of such deficiency in literature, the current study attempted to assess the efficacy and safety of IV lidocaine vis-à-vis standard analgesics like opioids and non-steroidal anti-inflammatory drugs (NSAIDs) for pain control in the ED.

\section{MATERIALS AND METHODS}

The PRISMA statement (Preferred Reporting Items for Systematic Reviews and Meta-analyses) (18) and the Cochrane Handbook for Systematic Reviews of Intervention (19) were followed during the conduct of this review. The research question to be answered was: What is the efficacy of IV lidocaine vs. standard analgesics for pain management in the emergency department?

\section{Literature Search}

A search strategy was designed with the help of the medical librarian wherein the electronic databases of PubMed, Embase, ScienceDirect, CENTRAL, and Google Scholar were explored. The search limits were set from inception to 26th October 2021. We also search clinicaltrials.gov for any ongoing trial. However, excluded databases with articles preprints that have not been peer-reviewed. A mix of $\mathrm{MeSH}$ and free keywords used for the literature search included: "lidocaine," "lignocaine," "emergency," "pain," and "analgesic." The search strings used were "(((lidocaine) OR (lignocaine)) AND (analgesic)) AND (emergency)" and "(((lidocaine) OR (lignocaine)) AND (pain)) AND (emergency)." Two reviewers carried out the electronic search independent of each other. The primary search results were assessed initially by their titles and abstracts to identify citations requiring full-text analysis. The full texts of the articles were reviewed by the two reviewers independently based on the inclusion and exclusion criteria. Any disagreements were resolved by discussion. Furthermore, we also hand-searched the bibliography of included studies for any missed references.

\section{Inclusion Criteria}

Eligibility criteria for this review were structured using the PICOS (Population, Intervention, Comparison, Outcome, and Study design) framework. Details are as follows:

Population: Patients reporting to the ED for any kind of pain Intervention: IV lidocaine in any dose

Comparison: NSAIDs or opioids via any route and any dose (Control group)

Outcomes: Pain scores in the first $60 \mathrm{~min}$, use of rescue analgesics, and/or side-effects of the drugs.

Study design: Randomized controlled trials (RCTs) only

Exclusion criteria were: (1) Studies using IV lidocaine as an adjuvant to other analgesics (2) Studies not using a comparative analgesic drug or not using NSAIDS/opioids as a comparative drug (3) Non-RCTs and uncontrolled studies (4) Studies not reporting relevant outcomes (5) Editorials, review articles, and non-English language studies.

\section{Data Extraction and Risk of Bias Assessment}

Two reviewers extracted data independently using a data extraction sheet. Data regarding the first author, publication year, study location, cause of pain, inclusion criteria, sample size, mean 


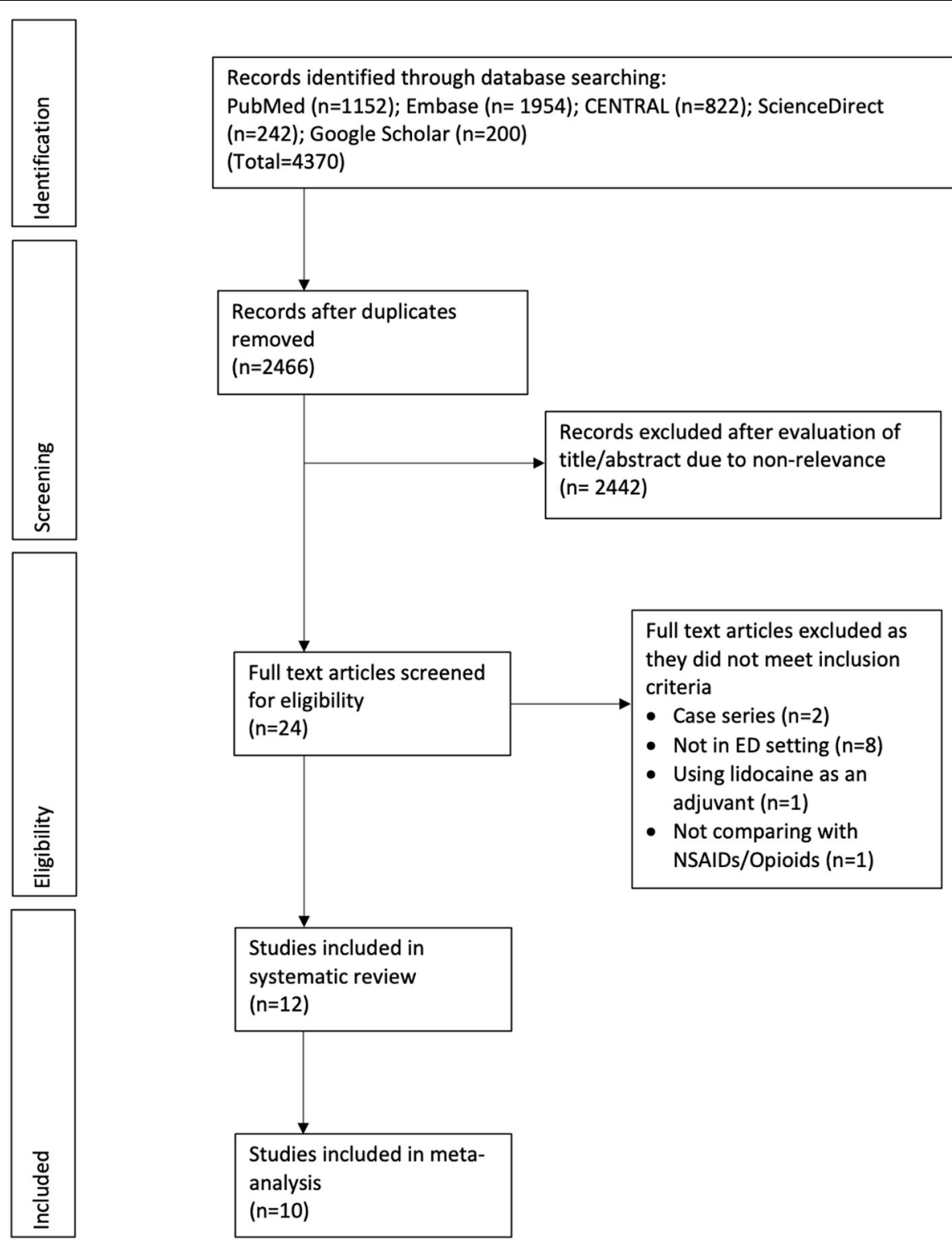

FIGURE 1 | Study flow chart.

age, gender details, the dose of IV lidocaine, type and dose of the comparative drug, and study outcomes were extracted. Primarily, we aimed to analyze the difference in pain scores in the first $60 \mathrm{~min}$ after drug administration. Secondary outcomes of interest were the need for rescue analgesics in the two groups and sideeffects associated with the interventions. A descriptive analysis was carried out if sufficient data were not available for a metaanalysis. The corresponding authors were not contacted for any missing data.

We used the recent Cochrane Collaboration's risk of bias assessment tool-2 to assess the quality of included RCTs (19). This was done by two reviewers independently. The following five domains were used for quality assessment: randomization process, deviation from intended intervention, missing outcome data, measurement of outcomes, and selection of reported result. Based on the risk of bias in individual domains, the overall bias was marked as "high risk", "some concerns," or "low risk." Any disagreements related to data extraction or quality assessment were resolved by discussion. We also assessed the certainty of the evidence using the Grading of Recommendations Assessment, Development, and Evaluation (GRADE) tool using the GRADEpro GDT software [GRADEpro Guideline Development Tool. McMaster University, 2020 (developed by Evidence Prime, Inc.)]. 
TABLE 1 | Details of included studies.

\begin{tabular}{|c|c|c|c|c|c|c|c|c|c|c|c|c|}
\hline \multirow[t]{2}{*}{ Study } & \multirow[t]{2}{*}{ Location } & \multirow[t]{2}{*}{$\begin{array}{l}\text { Cause } \\
\text { of pain }\end{array}$} & \multirow[t]{2}{*}{$\begin{array}{l}\text { Inclusion } \\
\text { criteria }\end{array}$} & \multirow[t]{2}{*}{$\begin{array}{l}\text { IV Lidocaine } \\
\text { dose }\end{array}$} & \multirow[t]{2}{*}{$\begin{array}{l}\text { Control } \\
\text { group drug }\end{array}$} & \multicolumn{2}{|c|}{$\begin{array}{l}\text { Sample } \\
\text { size }\end{array}$} & \multicolumn{2}{|l|}{$\begin{array}{c}\text { Mean } \\
\text { age (years) }\end{array}$} & \multicolumn{2}{|c|}{$\begin{array}{c}\text { Male } \\
\text { gender (\%) }\end{array}$} & \multirow[t]{2}{*}{ Study conclusions } \\
\hline & & & & & & $\mathbf{L}$ & C & $\mathbf{L}$ & C & $\mathbf{L}$ & C & \\
\hline Gur et al. (22) & Turkey & Migraine & $\begin{array}{l}\text { Adult patients } \\
\text { attending ED with } \\
\text { migraine attacks with at } \\
\text { least a 1-year history of } \\
\text { migraine }\end{array}$ & $\begin{array}{l}1.5 \mathrm{mg} / \mathrm{kg} \text { bolus } \\
\text { followed by } 1 \\
\mathrm{mg} / \mathrm{kg} / \mathrm{h} \text { infusion for } \\
30 \mathrm{~min} \text { and } 0.5 \\
\mathrm{mg} / \mathrm{kg} / \mathrm{h} \text { for next } \\
30 \mathrm{~min}\end{array}$ & $\begin{array}{l}\text { Normal saline bolus } \\
\text { followed by infusion } \\
\text { of IV dexketoprofen } \\
50 \mathrm{mg}\end{array}$ & 50 & 50 & $43[33-55]$ & 37 [33-54] & 38 & 46 & $\begin{array}{l}\text { IV lidocaine can be } \\
\text { an alternative } \\
\text { modality to manage } \\
\text { migraine headaches }\end{array}$ \\
\hline Akbas et al. (21) & Turkey & $\begin{array}{l}\text { Tension- } \\
\text { type } \\
\text { headache }\end{array}$ & $\begin{array}{l}\text { Adult patients attending } \\
\text { ED with episodic } \\
\text { tension-type headache }\end{array}$ & $1.5 \mathrm{mg} / \mathrm{kg}$ & $\begin{array}{l}\text { IV dexketoprofen } \\
50 \mathrm{mg}\end{array}$ & 60 & 60 & 43 [29-50.3] & $43[30-54]$ & 66.7 & 58.3 & $\begin{array}{l}\text { IV lidocaine can be } \\
\text { useful to manage } \\
\text { tension-type } \\
\text { headaches }\end{array}$ \\
\hline Akhgar et al. (26) & Iran & $\begin{array}{l}\text { Suspected } \\
\text { biliary } \\
\text { colic }\end{array}$ & $\begin{array}{l}\text { Adult patients attending } \\
\text { ED with right upper } \\
\text { quadrant pain with } \\
\text { severity }>5 \text { on NRS }\end{array}$ & $100 \mathrm{mg}$ & IV morphine 5 mg & 51 & 53 & $44.13 \pm 14.98$ & $44.3 \pm 12.78$ & 49 & 45 & $\begin{array}{l}\text { No significant } \\
\text { difference between } \\
\text { lidocaine and } \\
\text { morphine for pain } \\
\text { relief }\end{array}$ \\
\hline Motov et al. (25) & USA & $\begin{array}{l}\text { Renal } \\
\text { colic }\end{array}$ & $\begin{array}{l}\text { Adult patients attending } \\
\text { ED with acute flank } \\
\text { pain, abdominal pain, } \\
\text { or back pain suspected } \\
\text { to be due to renal colic }\end{array}$ & $1.5 \mathrm{mg} / \mathrm{kg}$ & IV ketorolac $30 \mathrm{mg}$ & 50 & 50 & $39.34 \pm 10.95$ & $42.34 \pm 10.47$ & 54 & 56 & $\begin{array}{l}\text { IV ketorolac was } \\
\text { superior to IV } \\
\text { lidocaine for pain } \\
\text { relief }\end{array}$ \\
\hline Chinn et al. (27) & USA & $\begin{array}{l}\text { Acute } \\
\text { abdominal }\end{array}$ & $\begin{array}{l}\text { Adult patients with } \\
\text { acute ( }<7 \text { days) and } \\
\text { severe (requiring IV } \\
\text { opioids) abdominal pain }\end{array}$ & $120 \mathrm{mg}$ & $\begin{array}{l}\text { IV hydromorphone } \\
1 \mathrm{mg}\end{array}$ & 77 & 77 & $42 \pm 12$ & $40 \pm 13$ & 30 & 43 & $\begin{array}{l}\text { IV hydromorphone } \\
\text { was superior to IV } \\
\text { lidocaine for pain } \\
\text { control }\end{array}$ \\
\hline $\begin{array}{l}\text { Clattenburg et al. } \\
\text { (28) }\end{array}$ & USA & $\begin{array}{l}\text { Unknown } \\
\text { cause }\end{array}$ & $\begin{array}{l}\text { Adult patients with pain } \\
\text { of severity } \geq 7 \text { on NRS }\end{array}$ & $\begin{array}{l}1.5 \mathrm{mg} / \mathrm{kg} \text { bolus and } \\
1.5 \mathrm{mg} / \mathrm{kg} \text { infusion } \\
\text { over } 50 \mathrm{~min}\end{array}$ & $\begin{array}{l}\text { IV morphine based } \\
\text { on physicians } \\
\text { discretion }\end{array}$ & 16 & 16 & 50 [36.5-59.5] & 45.5 [34-59.5] & 50 & 44 & $\begin{array}{l}\text { No significant } \\
\text { difference between } \\
\text { lidocaine and } \\
\text { morphine for pain } \\
\text { relief }\end{array}$ \\
\hline $\begin{array}{l}\text { Farahmand et al. } \\
\text { (30) }\end{array}$ & Iran & Traumatic & $\begin{array}{l}\text { Adult patients with } \\
\text { acute extremity injury } \\
\text { and pain score of }>4 \\
\text { on NRS }\end{array}$ & $150 \mathrm{mg}$ & IV morphine $10 \mathrm{mg}$ & 25 & 25 & $31.4 \pm 8.73$ & $31.16 \pm 8.7$ & 76 & 80 & $\begin{array}{l}\text { IV lidocaine is not } \\
\text { superior to IV } \\
\text { morphine for pain } \\
\text { control }\end{array}$ \\
\hline $\begin{array}{l}\text { Motamed and } \\
\text { Verki (29) }\end{array}$ & Iran & $\begin{array}{l}\text { Renal } \\
\text { colic }\end{array}$ & $\begin{array}{l}\text { Adult patients with } \\
\text { acute colicky flank pain }\end{array}$ & $1.5 \mathrm{mg} / \mathrm{kg}$ & IV fentanyl $1.5 \mu \mathrm{g} / \mathrm{kg}$ & 45 & 45 & $39.08 \pm 6.64$ & $34.08 \pm 9.49$ & 86.7 & 93.3 & $\begin{array}{l}\text { No difference in pain } \\
\text { scores between the } \\
\text { two drugs but higher } \\
\text { treatment failure with } \\
\text { IV lidocaine }\end{array}$ \\
\hline
\end{tabular}

(Continued) 


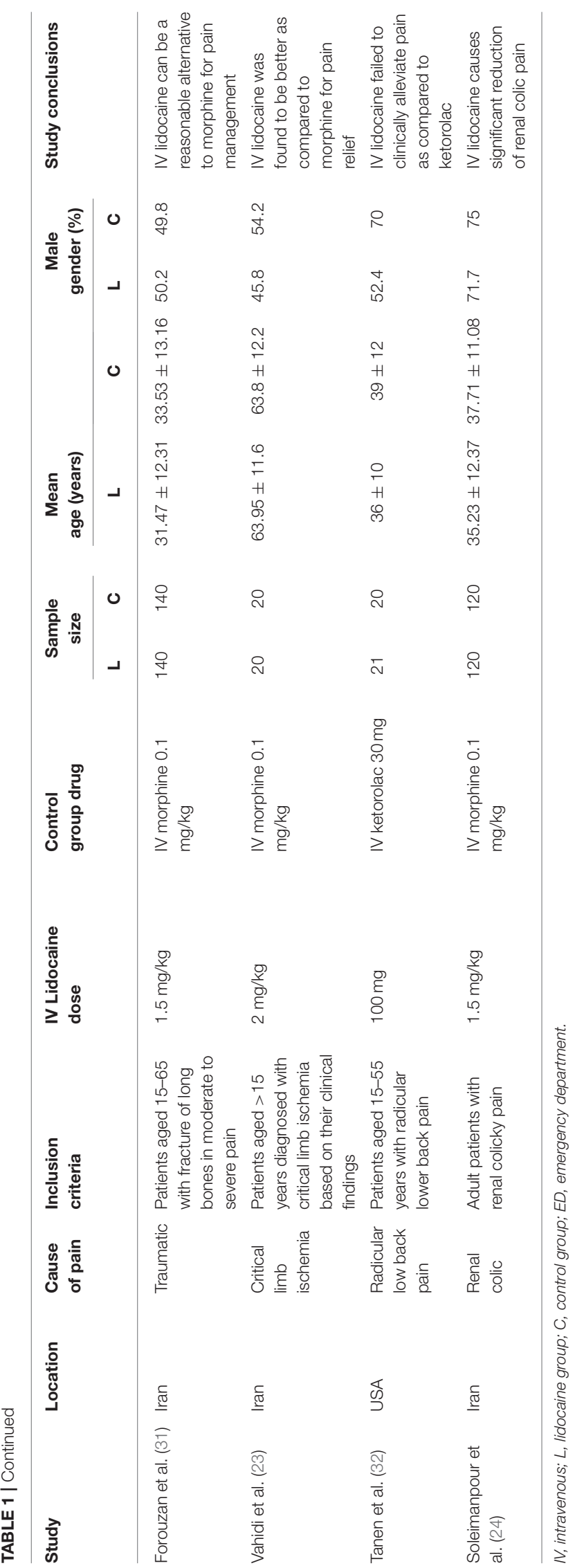

\section{Statistical Analysis}

"Review Manager" (RevMan, version 5.3; Nordic Cochrane Centre [Cochrane Collaboration], Copenhagen, Denmark; 2014) was used for the meta-analysis. Pain scores at different time intervals were summarized using mean Difference (MD) with 95\% confidence intervals (CI). Need for rescue analgesics and side-effects were summarized using odds ratios (OR) with 95\% CI. For studies reporting data only in graphical format, Engauge Digitizer Version 12.1 was used to extract data. Median, range and interquartile range data was converted into mean and standard deviation (SD) when required using the method of Wan et al. (20). Heterogeneity was assessed using the $I^{2}$ statistic. $I^{2}$ values of $25-50 \%$ represented low, values of 50 $75 \%$ medium, and more than $75 \%$ represented substantial heterogeneity. However, irrespective of the heterogeneity we preferred to use a random-effects model for our meta-analysis as the included studies were conducted on different populations with significant methodological heterogeneity. Due to a limited number of studies in the meta-analysis $(<10)$, funnel plots were not used to assess publication bias. Sub-group analyses based on the type of pain and type of comparative drug (opioid/NSAID) were also performed if there were at least 2 studies in each subgroup. We grouped studies reporting pain of abdominal origin (including biliary colic, renal colic) and musculoskeletal pain separately to separately assess the efficacy of IV lidocaine for each pain type.

\section{RESULTS}

\section{Details of Included Studies}

The number of search results at each stage is summarized in Figure 1. We reviewed a total of 2,466 unique records. Of these 2,442 were excluded based on title and abstract screening. Twenty-four articles were analyzed by their full-text and 12 were excluded with reasons. A total of 12 RCTs fulfilled the inclusion criteria and were analyzed in this review (21-32). The agreement between the two reviewers on inclusion of the studies was high (kappa 0.9). Baseline details extracted from the studies are presented in Table 1. A total of 1,351 patients were included in these 12 RCTs. All included trials were conducted either in Iran, Turkey or the USA. The cause of pain varied across studies and included abdominal pain, renal or biliary colic, traumatic pain, radicular low back pain, critical limb ischemia, migraine, tensiontype headache, and pain of unknown origin. In studies using a fixed dose of lidocaine the dosage ranged from 100 to $150 \mathrm{mg}$ while in studies using weight-based dosage, it ranged from 1.5 to $2 \mathrm{mg} / \mathrm{kg}$. IV morphine was the most common comparative drug while hydromorphone, fentanyl, and ketorolac (all administered IV) were used in the control group in one trial each. Two recent studies used IV dexketoprofen in the control group. Two trials of Motamed et al. (29) and Forouzan et al. (31) did not report pain scores as mean and SD but reported the number of patients with mild, moderate, and severe pain at different time intervals. The secondary outcome in both trials was treatment failure defined as lack of 3-point reduction of pain scores on Visual Analog Scale (VAS). Analyzing their results descriptively, both studies did not find any difference in the number of patients with different pain 


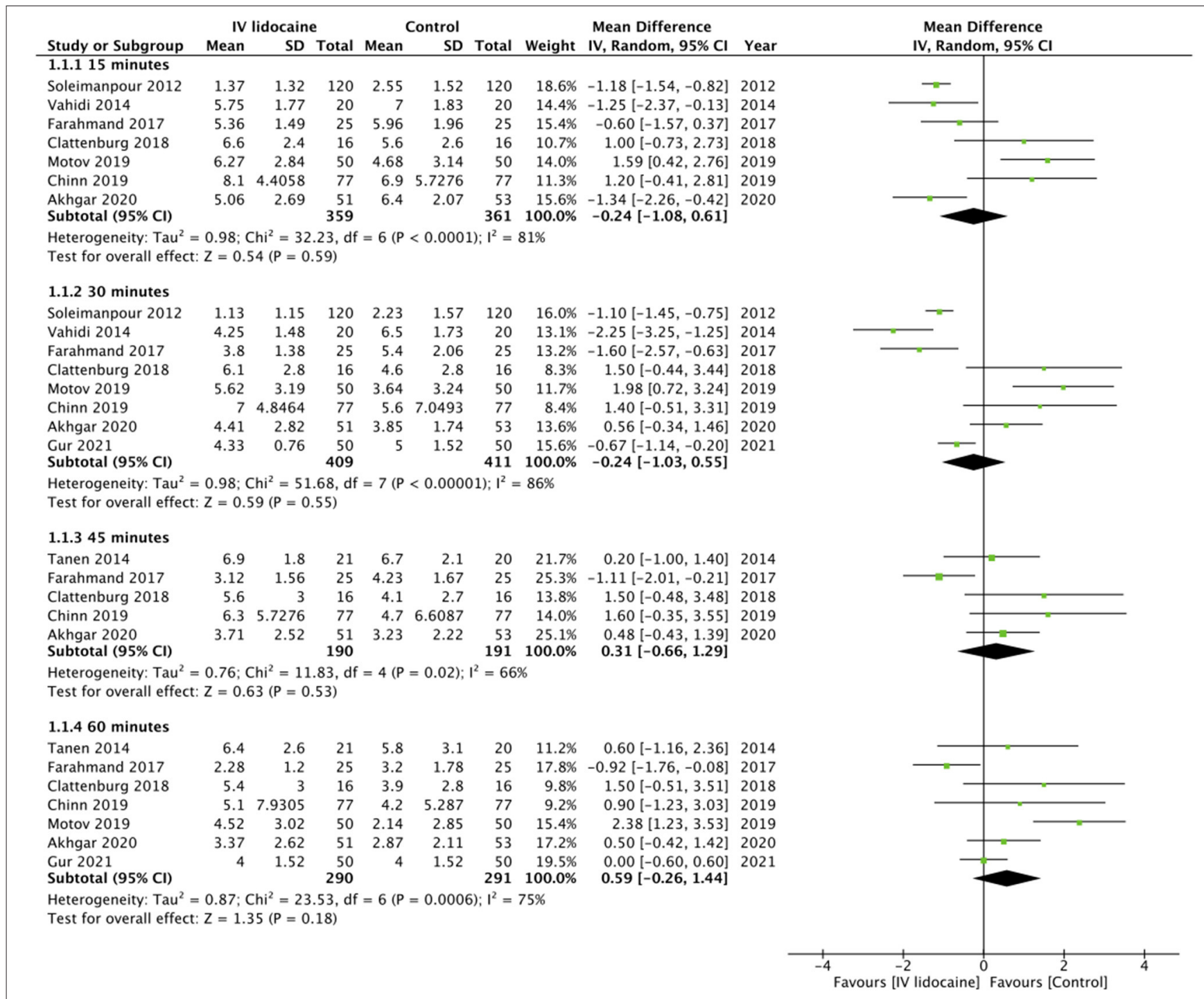

FIGURE 2 | Meta-analysis of pain scores at different time points between IV lidocaine and control groups.

intensities at 15 and $30 \mathrm{~min}$. While Motamed et al. (29) noted higher failure rates with IV lidocaine, Forouzan et al. (31) found higher failure rates in the control group. Another study of Akbas et al. (21) reported only change in pain scores at different time intervals. The authors noted significantly greater reduction of pain scores with IV lidocaine at 20,30, 60, 90, and $120 \mathrm{~min}$ as compared to IV dexketoprofen.

\section{Meta-Analysis}

On pooled analysis, we found no statistically significant difference in pain scores between IV lidocaine and control group at $15 \mathrm{~min}$ (MD: $-0.2495 \% \mathrm{CI}:-1.08,0.61 I^{2}=81 \% p=0.59$ ), $30 \min \left(\mathrm{MD}:-0.2495 \% \mathrm{CI}:-1.03,0.55 I^{2}=86 \% p=0.55\right.$ ), $45 \min \left(\mathrm{MD}: 0.3195 \% \mathrm{CI}:-0.66,1.29 I^{2}=66 \% p=0.53\right.$ ), and $60 \mathrm{~min}$ (MD: 0.59 95\% CI: $-0.26,1.44 I^{2}=75 \% p=0.18$ ) (Figure 2). GRADE assessment of the certainty of the evidence was "moderate" (Supplementary Table 1). On subgroup analysis based on the origin of pain, there was no statistically significant difference in pain scores between the two groups for studies on abdominal pain at any time point (Table 2). However, on analysis of just two studies on musculoskeletal pain, we noted significantly lower pain scores with IV lidocaine as compared to the control group. Similarly, subgroup analysis based on the type of control drug, we noted no difference in pain scores at 30 and $60 \mathrm{~min}$ between IV lidocaine and opioids or NSAIDs (Table 2).

There was no statistically significant difference in the need for rescue analgesics between the two groups (OR: 1.45 95\% CI: 0.82, $2.56 I^{2}=41 \% p=0.20$ ) (Figure 3). The certainty of evidence based on GRADE was "low" (Supplementary Table 1). But on subgroup analysis, the need for rescue analgesics was significantly higher with IV lidocaine in studies on abdominal pain but not for musculoskeletal pain (Table 2). Subgroup analysis based in the type of control group drug revealed no difference between the two groups. 
TABLE 2 | Results of sub-group analysis.

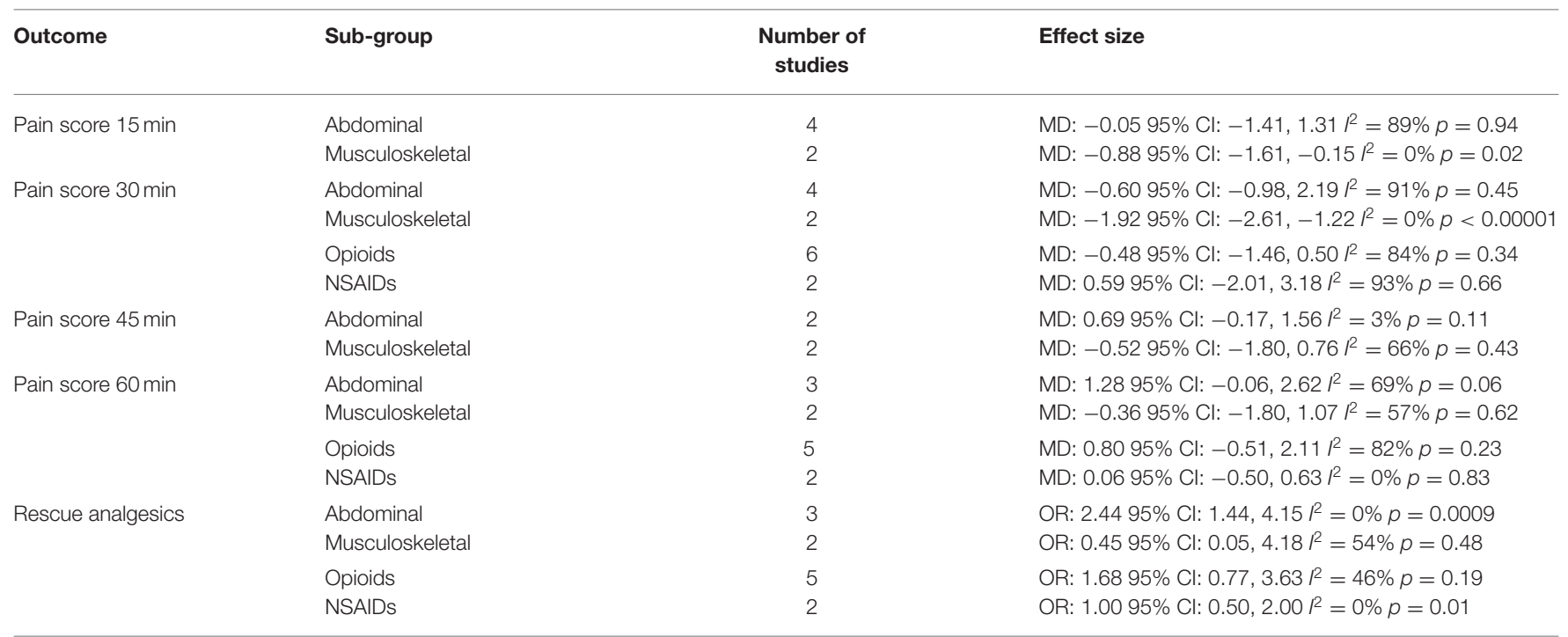

MD, mean difference; OR, odds ratio; Cl, confidence intervals; NSAIDs, Non-steroidal anti-inflammatory drugs.

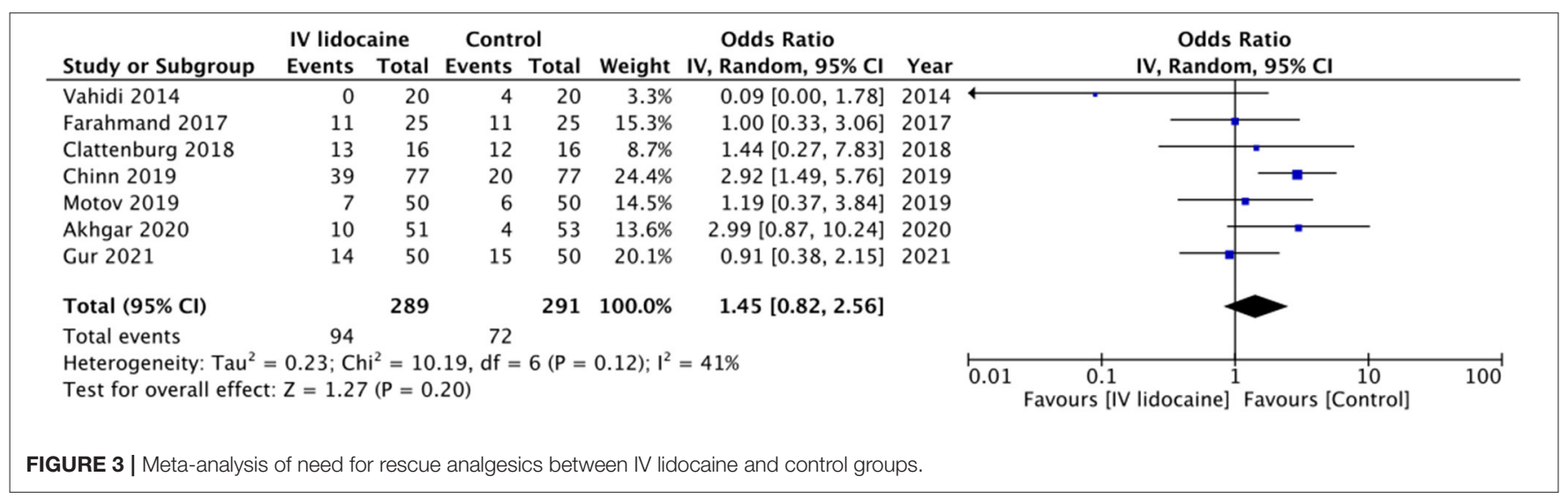

Details of side-effects reported by included studies are presented in Table 3. On meta-analysis, there was no statistically significant difference in the incidence of side-effects between the two study groups (OR: 1.09 95\% CI: $0.59,2.02 I^{2}=48 \% p=0.78$ ) (Figure 4). The certainty of evidence based on GRADE was "moderate" (Supplementary Table 1).

\section{Risk of Bias}

The risk of bias summary of the included studies is presented in Table 4. Nine studies were considered to have a "low" overall risk of bias. The study of Chinn et al. (27) was unblinded and therefore considered to have a "high" risk of bias for deviation from intended intervention and measurement of outcomes. The two trials $(29,31)$ not included in the meta-analysis were considered to have a "high" overall risk of bias due to the selection of reported results. These trials did not use standard methods of reporting pain outcomes and did not present complete outcome data.

\section{DISCUSSION}

Treatment of pain is an important yet complex problem in an ED. While managing this symptom, the clinician has to not only make a quick diagnosis of the origin of pain but also take into account the past medical history, drug history, and severity of the problem to prescribe an optimal analgesic. On account of several apprehensions amongst healthcare professionals regarding the opioid epidemic (33), research in the past decade has focussed on providing an optimal and safe non-opioid analgesic for routine use in the ED (34). The 2017 policy statement by the American College of Emergency Physicians also recommends that the first intervention for acute pain in the ED should be a non-opioid drug (35). Indeed, the second most commonly prescribed analgesics are NSAIDs and their use is gradually increasing for the management of pain in an emergency setting (36). According to a systematic review and meta-analysis by Pathan et al. (37), the efficacy of NSAIDs is equivalent to opioids for the management of renal colic and they can be used as a suitable alternative for the management of colicky pain in the ED. 
TABLE 3 | Details of adverse events reported by included studies.

\begin{tabular}{|c|c|c|}
\hline Study & Lidocaine & Control \\
\hline Akhgar et al. (26) & Dizziness (9.8\%) & Vomiting (7.5\%) \\
\hline Motov et al. (25) & $\begin{array}{l}\text { Dizziness } \\
\text { Nausea/Nomiting } \\
\text { Perioral numbness } \\
\text { Tinnitus } \\
\text { Headache } \\
\text { Epigastric pain } \\
\text { Drowsiness }\end{array}$ & $\begin{array}{l}\text { Dizziness } \\
\text { Nausea/omiting } \\
\text { Headache } \\
\text { Epigastric pain }\end{array}$ \\
\hline Chinn et al. (27) & $\begin{array}{l}\text { Dizziness }(5 \%) \\
\text { Drowsiness (8\%) } \\
\text { Headache (8\%) } \\
\text { Nausea }(12 \%) \\
\text { Pruritis (1\%) }\end{array}$ & $\begin{array}{l}\text { Dizziness }(14 \%) \\
\text { Drowsiness (4\%) } \\
\text { Headache }(3 \%) \\
\text { Nausea }(13 \%) \\
\text { Pruritis }(2 \%)\end{array}$ \\
\hline Clattenburg et al. (28) & $\begin{array}{l}\text { Perioral numbness (6.3\%) } \\
\text { Nausea }(6.3 \%)\end{array}$ & $\begin{array}{l}\text { Nausea }(25 \%) \\
\text { Pruritis }(6.3 \%) \\
\text { Bradycardia (6.3\%) }\end{array}$ \\
\hline Farahmand et al. (30) & Vomiting (4\%) & Vomiting (4\%) \\
\hline Soleimanpour et al. (24) & $\begin{array}{l}\text { Perioral numbness }(2.5 \%) \\
\text { Transient dizziness }(8.3 \%) \\
\text { Dysarthria }(1.7 \%)\end{array}$ & $\begin{array}{l}\text { Hypotension (2.5\%) } \\
\text { Vertigo }(1.7 \%) \\
\text { Nausea }(7.5 \%) \\
\text { Vomiting }(1.6 \%)\end{array}$ \\
\hline
\end{tabular}

Figures in parenthesis indicate percentage of patients experiencing the adverse event (where data was available).

Another recent study by Yin et al. (38) has shown that NSAIDs are most suitable for the management of musculoskeletal pain. Despite their efficacy, there have been concerns regarding the use of NSAIDS for severe pain and the associated side effects of these drugs. Gastrointestinal bleeding/ulceration, renal injury, and platelet inhibition are known adverse events linked with NSAIDs (39). In this context, an alternative drug like IV lidocaine can expand the spectrum of medications available to an emergency physician for the management of pain.

As seen in our systematic review, with the availability of only 12 trials, IV lidocaine has not been widely researched for pain management in the ED. However, the drug has been used on a wide range of patients including both musculoskeletal and abdominal pain. On pooled analysis of the trials, we found no difference in pain scores between patients receiving IV lidocaine or standard analgesics at different time points in the first hour of drug administration. Interesting to note was that in the first $30 \mathrm{~min}$, there was a significant but small reduction of pain scores with IV lidocaine in studies on musculoskeletal pain but not for abdominal pain. Nevertheless, this should be interpreted with the concept of minimum clinically important difference (MCID). In 1989, Jaeschke et al. (40) bought forward the principle of MCID, which was defined as "the smallest difference in score in the domain of interest which participants perceive as beneficial and which would mandate, in the absence of troublesome side effects and costs, a change in the patient's management." This concept stresses the fact that the difference in pain scores achieved by the drug should be clinically relevant to the patient even if the $\mathrm{MD}$ is statistically significant (41). Considering the MD in our meta-analysis was very small, it may not be clinically relevant. Furthermore, we also noted that there was no difference in pain outcomes between IV lidocaine vs. opioid as well as IV lidocaine vs. NSAIDs. However, there were only limited number of studies in our subgroup analyses and the results should be interpreted cautiously. Another important parameter of assessing pain in any trial is the need for rescue analgesics which is a surrogate marker for the amount of pain experienced by the patient. We found that the need for rescue analgesics was higher at $33.4 \%$ in the IV lidocaine group as compared to $23.6 \%$ in the control group but with a non-significant difference. However, one has to note that the $95 \%$ CI of the meta-analysis on the need for rescue analgesics was wide (0.86-3.08) with the lower limit close to 1 and upper limit indicating a 3-fold increased use of rescue analgesics with IV lidocaine. Thus, while pain scores may not differ between the two groups, there was a tendency of increased use of rescue analgesics in the IV lidocaine group which affected the pain scores. Owing to the limited number of studies reporting data on the need for rescue analgesics and the wide 95\% CI the overall certainty of the evidence was downgraded and was deemed to be "low." On subgroup analysis, it was obvious that the need for rescue analgesics was significantly high in studies on abdominal pain with a similar albeit non-significant tendency in studies on musculoskeletal pain as well. However, we noted no difference in the need for rescue analgesics based on the type of control drug indicating similar efficacy of lidocaine as compared to both groups of analgesic drugs. However, this must be interpreted with caution due to limited number of studies in the subgroup analysis and further trials are needed to strengthen this comparison.

For comparing our results with prior literature, it can be noted that the use of IV lidocaine has been most commonly reported in a surgical setting (42). While the majority of studies on surgical patients indicate that lidocaine is an effective analgesic for postoperative pain control $(10,11)$, few trials have indicated that systemic lidocaine may offer no beneficial effect in the postoperative period $(43,44)$. However, it is important to note that majority of the studies assessing the efficacy of IV lidocaine in a surgical setting have compared the drug with placebo or used IV lidocaine as an adjunct to a baseline analgesic. Therefore, in the absence of a comparator drug, the analgesic property of IV lidocaine would be more evident. The results of the only trial assessing the efficacy of lidocaine as an adjunct in an emergency setting have shown that IV lidocaine is an effective adjuvant to morphine for managing renal colic pain in the ED (45). However, literature is scarce for direct comparison between IV lidocaine and other analgesics. In a small trial, Wu et al. (46) have shown that morphine is superior to IV lidocaine for managing post-amputation pain.

The use of IV lidocaine as a potential analgesic in the ED is accompanied by its inherent complications. Due to the associated cardiotoxicity and neurotoxicity, IV lidocaine should be cautiously used in patients with comorbidities like heart block, cardiac failure, or epilepsy (47). Furthermore, owing to its narrow therapeutic index constant ECG and blood pressure monitoring are needed following IV administration of lidocaine. Toxicity with lidocaine usually manifests as numbness of the tongue, metallic taste, drowsiness, and tinnitus. At higher doses, patients may experience visual disturbances, muscle twitching, and seizures (48). These effects are largely based on the dosage 


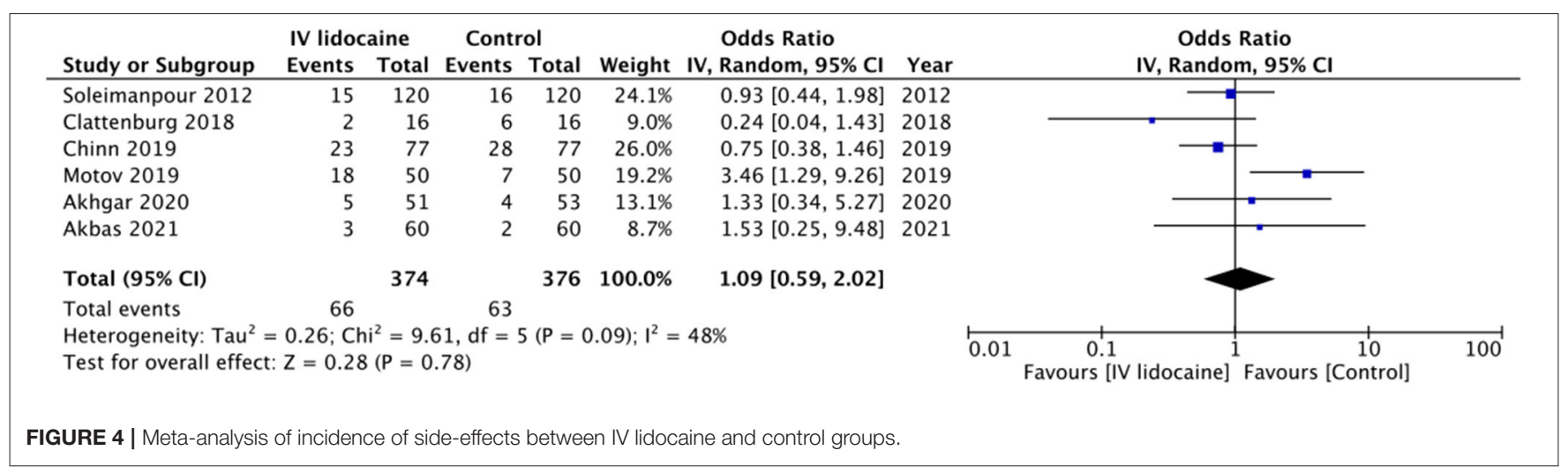

TABLE 4 | Risk of bias in included studies.

\begin{tabular}{|c|c|c|c|c|c|c|}
\hline Study & $\begin{array}{l}\text { Randomization } \\
\text { process }\end{array}$ & $\begin{array}{l}\text { Deviation from } \\
\text { intended } \\
\text { intervention }\end{array}$ & $\begin{array}{l}\text { Missing } \\
\text { outcome data }\end{array}$ & $\begin{array}{l}\text { Measurement of } \\
\text { outcomes }\end{array}$ & $\begin{array}{l}\text { Selection of } \\
\text { reported result }\end{array}$ & $\begin{array}{l}\text { Overall risk of } \\
\text { bias }\end{array}$ \\
\hline Gur et al. (22) & Low risk & Low risk & Low risk & Low risk & Low risk & Low risk \\
\hline Akbas et al. (21) & Low risk & Low risk & Low risk & Low risk & Low risk & Low risk \\
\hline Akhgar et al. (26) & Low risk & Low risk & Low risk & Low risk & Low risk & Low risk \\
\hline Motov et al. (25) & Low risk & Low risk & Low risk & Low risk & Low risk & Low risk \\
\hline Chinn et al. (27) & Some concerns & High risk & Low risk & High risk & Low risk & High risk \\
\hline Clattenburg et al. (28) & Low risk & Low risk & Low risk & Low risk & Low risk & Low risk \\
\hline Farahmand et al. (30) & Low risk & Low risk & Low risk & Low risk & Low risk & Low risk \\
\hline Motamed and Verki (29) & Low risk & Low risk & Low risk & Low risk & High risk & High risk \\
\hline Forouzan et al. (31) & Low risk & Low risk & Low risk & Low risk & High risk & High risk \\
\hline Vahidi et al. (23) & Low risk & Low risk & Low risk & Low risk & Low risk & Low risk \\
\hline Tanen et al. (32) & Low risk & Low risk & Low risk & Low risk & Low risk & Low risk \\
\hline Soleimanpour et al. (24) & Low risk & Low risk & Low risk & Low risk & Low risk & Low risk \\
\hline
\end{tabular}

of the drug use. While the exact dosage of IV lidocaine for pain control is not clear, usually a weight-based dose of 1.5-2 $\mathrm{mg} / \mathrm{kg}$ is utilized. A similar dose was used by the majority of studies in our review. Dizziness, perioral numbness, nausea were commonly noted in the lidocaine arm of the trials (49). However, there was no statistically significant difference in the incidence of side-effects between the two study groups and none of the studies reported any serious adverse events with lidocaine like bradycardia, hypotension, or seizures.

Our review has some limitations. Foremost, the number of trials available in the meta-analysis was not high. Two studies had to be excluded from the analysis due to differences in reporting of outcomes. Secondly, there was significant heterogeneity in the included studies concerning the diagnosis, dosage of lidocaine, and comparative drug used. An attempt was made to explore this heterogeneity using a subgroup analysis for the type of pain and type of control group analgesic. However, this reduced the power of the analysis. Thirdly, not all studies were high-quality and free of bias. The certainty of evidence provided by the review was not high and ranged from moderate-low. Lastly, all the included trials were conducted in just two countries. This significantly limits the generalizability of the results of our review.

Nevertheless, our study is the first meta-analysis to assess the efficacy and safety of IV lidocaine for pain control in an emergency setting. Unlike prior reviews $(15,16)$, we included only RCTs to present the best possible evidence to the readers. Subgroup analysis and GRADE assessment was done to provide clarity on the results.

To conclude, our results indicate that IV lidocaine can be considered as an alternative analgesic for pain control in the ED. However, its efficacy may not be higher than standard analgesics. Further RCTs with a large sample size are needed to corroborate the current conclusions.

\section{DATA AVAILABILITY STATEMENT}

The raw data supporting the conclusions of this article will be made available by the authors, without undue reservation.

\section{AUTHOR CONTRIBUTIONS}

JZ, JH, and LM: conceptualized and designed the study and analyzed the data. GY, KQ, and YZ: literature search. GY, $\mathrm{KQ}$, and $\mathrm{SH}$ : writing-original draft preparation. $\mathrm{YZ}$ and $\mathrm{SH}$ : writing-reviewing and editing. All authors read and approved the final manuscript. 


\section{FUNDING}

$\begin{array}{lcrrr}\text { This study } \quad \text { was funded } & \text { by } & \text { Project } \\ \text { of Shaoxing } & \text { Municipal } & \text { Science } & \text { and } \\ \text { Technology (2018C30078). } & \end{array}$

Technology (2018C30078).

\section{REFERENCES}

1. Todd KH, Ducharme J, Choiniere M, Crandall CS, Fosnocht DE, Homel $\mathrm{P}$, et al. Pain in the emergency department: results of the pain and emergency medicine initiative (PEMI) multicenter study. J Pain. (2007) 8:4606. doi: 10.1016/j.jpain.2006.12.005

2. Kim HS, Heard KJ, Heard S, Hoppe JA. Opioid prescription fill rates after emergency department discharge. Am J Heal Pharm. (2016) 73:9027. doi: 10.2146/ajhp150528

3. Smith BC, Vigotsky AD, Apkarian AV, Schnitzer TJ. Temporal factors associated with opioid prescriptions for patients with pain conditions in an urban emergency department. JAMA Netw Open. (2020) 3:e200802. doi: 10.1001/jamanetworkopen.2020.0802

4. Butler MM, Ancona RM, Beauchamp GA, Yamin CK, Winstanley EL, Hart KW, et al. Emergency department prescription opioids as an initial exposure preceding addiction. Annals Emergency Med. (2016) 68:2028. doi: 10.1016/j.annemergmed.2015.11.033

5. Hoppe JA, Kim H, Heard K. Association of emergency department opioid initiation with recurrent opioid use. Ann Emerg Med. (2015) 65:49399.e4. doi: 10.1016/j.annemergmed.2014.11.015

6. Lalic S, Gisev N, Bell JS, Korhonen MJ, Ilomäki J. Predictors of persistent prescription opioid analgesic use among people without cancer in Australia. Br J Clin Pharmacol. (2018) 84:1267-78. doi: 10.1111/bcp.13556

7. Nichols LM, Pedroza JA, Fleming CM, O'Brien KM, Tanner-Smith EE. Social-ecological predictors of opioid use among adolescents with histories of substance use disorders. Front Psychol. (2021) 12:686414. doi: 10.3389/fpsyg.2021.686414

8. Wood JN, Boorman JP, Okuse K, Baker MD. Voltage-gated sodium channels and pain pathways. J Neurobiol. (2004) 61:55-71. doi: 10.1002/neu.20094

9. Weibel S, Jelting Y, Pace NL, Helf A, Eberhart LHJ, Hahnenkamp $\mathrm{K}$, et al. Continuous intravenous perioperative lidocaine infusion for postoperative pain and recovery in adults. Cochrane Database Syst Rev. (2018) 2018:CD009642. doi: 10.1002/14651858.CD009642.pub3

10. Sun Y, Li T, Wang N, Yun Y, Gan TJ. Perioperative systemic lidocaine for postoperative analgesia and recovery after abdominal surgery: a metaanalysis of randomized controlled trials. Dis Colon Rectum. (2012) 55:118394. doi: 10.1097/DCR.0b013e318259bcd8

11. Lovett-Carter D, Kendall MC, Park J, Ibrahim-Hamdan A, Crepet S, De Oliveira G. The effect of systemic lidocaine on post-operative opioid consumption in ambulatory surgical patients: a metaanalysis of randomized controlled trials. Perioper Med. (2021) 10:11. doi: 10.1186/s13741-021-00181-9

12. Zhu B, Zhou X, Zhou Q, Wang H, Wang S, Luo K. Intra-venous lidocaine to relieve neuropathic pain: a systematic review and meta-analysis. Front Neurol. (2019) 10:954. doi: 10.3389/fneur.2019.00954

13. Lee JT, Sanderson CR, Xuan W, Agar M. Lidocaine for cancer pain in adults: a systematic review and meta-analysis. J Palliat Med. (2019) 22:32634. doi: 10.1089/jpm.2018.0257

14. Golzari SE, Soleimanpour H, Mahmoodpoor A, Safari S, Ala A. Lidocaine and pain management in the emergency department: a review article. Anesthesiol Pain Med. (2014) 4:e15444. doi: 10.5812/aapm.15444

15. e Silva LOJ, Scherber K, Cabrera D, Motov S, Erwin PJ, West CP, et al. Safety and efficacy of intravenous lidocaine for pain management in the emergency department: a systematic review. Ann Emerg Med. (2018) 72:13544.e3. doi: 10.1016/j.annemergmed.2017.12.014

16. Masic D, Liang E, Long C, Sterk EJ, Barbas B, Rech MA. Intravenous lidocaine for acute pain: a systematic review. Pharmacotherapy. (2018) 38:1250-9. doi: 10.1002/phar.2189

\section{SUPPLEMENTARY MATERIAL}

The Supplementary Material for this article can be found online at: https://www.frontiersin.org/articles/10.3389/fmed. 2021.706844/full\#supplementary-material

17. Miller AC, Faza C, Castro Bigalli AA, Khan AM, Sewell KA, King A, et al. Intravenous amide anesthetics to treat pain associated with renal colic in the emergency department: a systematic review. Arch Acad Emerg Med. (2020) 8:1-11.

18. Moher D, Liberati A, Tetzlaff J, Altman DG, PRISMA Group. Preferred reporting items for systematic reviews and meta-analyses: the PRISMA statement. PLoS Med. (2009) 6:e1000097. doi: 10.1371/journal.pmed.1000097

19. Higgins J, Thomas J, Chandler J, Cumpston M, Li T, Page M, Welch V. Cochrane Handbook for Systematic Reviews of Interventions. Version 6. Cochrane (2019). doi: 10.1002/9781119536604

20. Wan X, Wang W, Liu J, Tong T. Estimating the sample mean and standard deviation from the sample size, median, range and/or interquartile range. BMC Med Res Methodol. (2014) 14:135. doi: 10.1186/1471-228814-135

21. Akbas I, Kocak AO, Akgol Gur ST, Oral Ahiskalioglu E, Dogruyol S, Dolanbay T, et al. Lidocaine versus dexketoprofen in treatment of tensiontype headache: a double-blind randomized controlled trial. Am J Emerg Med. (2021) 41:125-9. doi: 10.1016/j.ajem.2020.12.057

22. Gur STA, Ahiskalioglu EO, Aydin ME, Kocak AO, Aydin P, Ahiskalioglu A. Intravenous lidocaine vs. NSAIDs for migraine attack in the ED: a prospective, randomized, double-blind study. Eur J Clin Pharmacol. (2021) 8:e27. doi: 10.1007/s00228-021-03219-5

23. Vahidi E, Shakoor D, Meybodi MA, Saeedi M. Comparison of intravenous lidocaine versus morphine in alleviating pain in patients with critical limb ischaemia. Emerg Med J. (2015) 32:516-9. doi: 10.1136/emermed-2014-203944

24. Soleimanpour H, Hassanzadeh K, Vaezi H, Golzari SEJ, Esfanjani RM, Soleimanpour M. Effectiveness of intravenous lidocaine versus intravenous morphine for patients with renal colic in the emergency department. BMC Urol. (2012) 12:13. doi: 10.1186/1471-2490-12-13

25. Motov S, Fassassi C, Drapkin J, Butt M, Hossain R, Likourezos A, et al. Comparison of intravenous lidocaine/ketorolac combination to either analgesic alone for suspected renal colic pain in the ED. Am J Emerg Med. (2020) 38:165-72. doi: 10.1016/j.ajem.2019.01.048

26. Akhgar A, Pouryousefi T, Nejati A, Rafiemanesh H, Hossein-nejad H. The efficacy of intravenous lidocaine and its side effects in comparison with intravenous morphine sulfate in patients admitted to the ED with right upper abdominal pain suspected of biliary colic. Am J Emerg Med. (2020) 26:264-8. doi: 10.1016/j.ajem.2020.04.010

27. Chinn E, Friedman BW, Naeem F, Irizarry E, Afrifa F, Zias E, et al. Randomized trial of intravenous lidocaine versus hydromorphone for acute abdominal pain in the emergency department. Ann Emerg Med. (2019) 74:233-40. doi: 10.1016/j.annemergmed.2019.01.021

28. Clattenburg EJ, Nguyen A, Yoo T, Flores S, Hailozian C, Louie D, Herring AA. Intravenous lidocaine provides similar analgesia to intravenous morphine for undifferentiated severe pain in the emergency department: a pilot, unblinded randomized controlled trial. Pain Med. (2019) 20:8349. doi: $10.1093 / \mathrm{pm} / \mathrm{pny} 031$

29. Motamed H, Verki MM. Intravenous lidocaine compared to fentanyl in renal colic painmanagement; a randomized clinical trial. Emerg (Tehran). (2017) 5:e82. doi: 10.22037/emergency.v5i1.18894

30. Farahmand S, Hamrah H, Arbab M, Sedaghat M, Basir Ghafouri H, BagheriHariri S. Pain management of acute limb trauma patients with intravenous lidocaine in emergency department. Am J Emerg Med. (2018) 36:12315. doi: 10.1016/j.ajem.2017.12.027

31. Forouzan A, Barzegari $\mathrm{H}$, Motamed H, Khavanin A, Shiri H. Intravenous lidocaine versus morphine sulfate in pain management for extremity fractures; a clinical trial. Emerg (Tehran). (2017) 5:e68. 
32. Tanen DA, Shimada M, Danish DC, Santos F Dos, Makela M, Riffenburgh RH. Intravenous lidocaine for the Emergency Department treatment of acute radicular low back pain, a randomized controlled trial. J Emerg Med. (2014) 47:119-24. doi: 10.1016/j.jemermed.2012.12.014

33. Axeen S, Seabury SA, Menchine M. Emergency department contribution to the prescription opioid epidemic. Ann Emerg Med. (2018) 71:65967.e3. doi: 10.1016/j.annemergmed.2017.12.007

34. Balzer N, McLeod SL, Walsh C, Grewal K. Low-dose Ketamine for acute pain control in the emergency department: a systematic review and meta-analysis. Acad Emerg Med. (2021) 28:444-54. doi: 10.1111/acem.14159

35. AC of EP (ACEP). Policy Statement - Optimizing the Treatment of Acute Pain in the Emergency Department. (2017). Available at: https://www.acep. org/globalassets/new-pdfs/policy-statements/optimizing-the-treatment-ofacute-pain-in-the-ed.pdf (accessed January 10, 2020).

36. Vijay A, Rhee TG, Ross JS. U.S. prescribing trends of fentanyl, opioids, and other pain medications in outpatient and emergency department visits from 2006 to 2015. Prev Med. (2019) 123:123-9. doi: 10.1016/j.ypmed.2019.03.022

37. Pathan SA, Mitra B, Cameron PA. A systematic review and meta-analysis comparing the efficacy of nonsteroidal anti-inflammatory drugs, opioids, and paracetamol in the treatment of acute renal colic. Eur Urol. (2018) 73:583-95. doi: 10.1016/j.eururo.2017.11.001

38. Yin $\mathrm{X}$, Wang $\mathrm{X}, \mathrm{He} \mathrm{C}$. Comparative efficacy of therapeutics for traumatic musculoskeletal pain in the emergency setting: a network meta-analysis. $\mathrm{Am} \mathrm{J}$ Emerg Med. (2020) 46:424-9. doi: 10.1016/j.ajem.2020.10.038

39. Samcam I, Papa L. Acute Pain Management in the Emergency Department. In: Pain Management (InTech).

40. Jaeschke R, Singer J, Guyatt GH. Measurement of health status. Ascertaining the minimal clinically important difference. Control Clin Trials. (1989) 10:407-15. doi: 10.1016/0197-2456(89)90005-6

41. Olsen MF, Bjerre E, Hansen MD, Hilden J, Landler NE, Tendal B, Hróbjartsson A. Pain relief that matters to patients: systematic review of empirical studies assessing the minimum clinically important difference in acute pain. BMC Med. (2017) 15:1-18. doi: 10.1186/s12916-016-0775-3

42. Weibel S, Jokinen J, Pace NL, Schnabel A, Hollmann MW, Hahnenkamp K, et al. Efficacy and safety of intravenous lidocaine for postoperative analgesia and recovery after surgery: a systematic review with trial sequential analysis. $\mathrm{Br} \mathrm{J}$ Anaesth. (2016) 116:770-83. doi: 10.1093/bja/aew101

43. Dewinter G, Moens P, Fieuws S, Vanaudenaerde B, Van De Velde M, Rex S. Systemic lidocaine fails to improve postoperative morphine consumption, postoperative recovery and quality of life in patients undergoing posterior spinal arthrodesis. A double-blind, randomized, placebo-controlled trial. Br J Anaesth. (2017) 118:576-85. doi: 10.1093/bja/ aex038
44. Dewinter GBE, Teunkens A, Vermeulen K, Al Tmimi L, Van De Velde M, Rex S. Systemic lidocaine fails to improve postoperative pain, but reduces time to discharge readiness in patients undergoing laparoscopic sterilization in daycase surgery: a double-blind, randomized, placebo-controlled trial. Reg Anesth Pain Med. (2016) 41:362-7. doi: 10.1097/AAP.0000000000000398

45. Firouzian A, Alipour A, Rashidian Dezfouli H, Zamani Kiasari A, Gholipour Baradari A, Emami Zeydi A, et al. Does lidocaine as an adjuvant to morphine improve pain relief in patients presenting to the ED with acute renal colic? A double-blind, randomized controlled trial. in Am J Emergency Med. (2016) 34:443-8. doi: 10.1016/j.ajem.2015.11.062

46. Wu CL, Tella P, Staats PS, Vaslav R, Kazim DA, Wesselmann U, et al Analgesic effects of intravenous lidocaine and morphine on postamputation pain: A randomized double-blind, active placebo-controlled, crossover trial Anesthesiology. (2002) 96:841-8. doi: 10.1097/00000542-200204000-00010

47. Hasan B, Asif T, Hasan M. Lidocaine-induced systemic toxicity: a case report and review of literature. Cureus. (2017) 9:e1275. doi: 10.7759/cureus.1275

48. Foo I, Macfarlane AJR, Srivastava D, Bhaskar A, Barker H, Knaggs R, et al. The use of intravenous lidocaine for postoperative pain and recovery: international consensus statement on efficacy and safety. Anaesthesia. (2021) 76:238-50. doi: 10.1111/anae.15270

49. Tremont-Lukats IW, Hutson PR, Backonja MM. A randomized, doublemasked, placebo-controlled pilot trial of extended IV lidocaine infusion for relief of ongoing neuropathic pain. Clin J Pain. (2006) 22:26671. doi: 10.1097/01.ajp.0000169673.57062.40

Conflict of Interest: The authors declare that the research was conducted in the absence of any commercial or financial relationships that could be construed as a potential conflict of interest.

Publisher's Note: All claims expressed in this article are solely those of the authors and do not necessarily represent those of their affiliated organizations, or those of the publisher, the editors and the reviewers. Any product that may be evaluated in this article, or claim that may be made by its manufacturer, is not guaranteed or endorsed by the publisher.

Copyright (c) 2022 Zhong, Hu, Mao, Ye, Qiu, Zhao and Hu. This is an open-access article distributed under the terms of the Creative Commons Attribution License (CC $B Y)$. The use, distribution or reproduction in other forums is permitted, provided the original author(s) and the copyright owner(s) are credited and that the original publication in this journal is cited, in accordance with accepted academic practice. No use, distribution or reproduction is permitted which does not comply with these terms. 